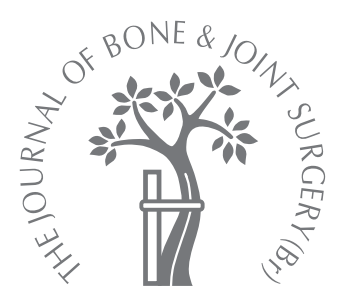

P. J. Yates,

B. J. Burston,

E. Whitley,

G. C. Bannister

From the Avon

Orthopaedic Centre, Bristol, England

In. J. Yates, BSc(Hons), MRCS, FRCS(Tr \& Orth), Consultant

Orthopaedic Surgeon \& Senior Lecturer

Department of Orthopaedics

and Trauma

Fremantle Hospital, Alma Road,

Fremantle, Western Australia

6160 , Australia.

घ. J. Burston, MBChB(Hons), BSc(Hons), MRCS, Specialist Registrar

E. Whitley, PhD, BSc(Hons),

MSc, Medical Statistician

G. C. Bannister, MD,

MCh(Orth), FRCSEd(Orth),

Consultant Orthopaedic

Surgeon

Avon Orthopaedic Centre,

Southmead Hospital,

Southmead Road,

Westbury-on-trym, Bristol

BS10 5NB, UK.

Correspondence should be sent to Mr P. J. Yates; e-mail: piersyates@hotmail.com

C2008 British Editorial Society of Bone and Joint Surgery doi:10.1302/0301-620X.90B1. $19546 \$ 2.00$

$J$ Bone Joint Surg $[\mathrm{Br}]$ 2008;90-B:16-22.

Received 11 April 2007;

Accepted after revision 31

August 2007

\title{
Collarless polished tapered stem
}

\author{
CLINICAL AND RADIOLOGICAL RESULTS AT A MINIMUM OF TEN \\ YEARS' FOLLOW-UP
}

\begin{abstract}
We retrospectively reviewed 175 patients (191 hips) who had undergone primary cemented total hip replacement between November 1992 and November 1995 using a collarless polished double-tapered femoral component after a minimum of ten years (mean 11.08; 10 to 12.8). All stems were implanted using contemporary cementing techniques with a distal cement restrictor, pressurised lavage, retrograde cementing with a gun and proximal pressurisation. Clinical outcome was assessed using the Harris Hip score. Radiological analysis was performed on calibrated plain radiographs taken in two planes. Complete radiological data on 110 patients (120 hips) and clinical follow-up on all the surviving 111 patients (122 hips) was available. The fate of all the hips was known.

At final follow-up, the mean Harris Hip score was 86 (47 to 100), and 87 of 116 patients $(75 \%)$ had good or excellent scores. Survival with revision of the stem for aseptic loosening as the endpoint was $100 \%$; and survival with revision of the stem for any reason was $\mathbf{9 5 . 9 \%}$ $(95 \%$ confidence interval 87.8 to 96.8$)$ at ten years. All the stems subsided vertically at the stem-cement interface in a predictable pattern, at an overall mean rate of $0.18 \mathrm{~mm}$ per year (0.02 to 2.16), but with a mean rate of $0.80 \mathrm{~mm}(0.02$ to 2.5$)$ during the first year. The mean total subsidence was $1.95 \mathrm{~mm}(0.21$ to 24$)$. Only three stems loosened at the cement-bone interface. There was excellent preservation of proximal femoral bone stock. There was a high incidence of Brooker III and IV heterotopic ossification affecting 25 patients (22\%).

The collarless polished tapered stem has an excellent clinical and radiological outcome at a minimum of ten years' follow-up. The pattern and magnitude of subsidence of the stem within the cement mantle occurred in a predictable pattern, consistent with the design philosophy.
\end{abstract}

The collarless polished tapered femoral prosthesis (Zimmer, Warsaw, Indiana) is doubletapered with a highly-polished surface and a rectangular proximal geometry. It was introduced into clinical practice in the late 1980s. It was originally manufactured in cobalt chrome for use in the United States, and in high-nitrogen stainless steel for use elsewhere. This configuration, like that of the original Exeter stem, from which its design was derived, allows limited subsidence of the stem within the cement mantle, resulting in an even transfer of load and conversion of shear forces into compressive forces according to the taper-slip principle. ${ }^{1}$ The broad proximal cross-section provides rotational stability and the progressive distally diminishing cross-section minimises the stress riser at the tip of the stem (Fig. 1). The important design differences between collarless polished tapered and the Exeter Universal stem are that the former stem has a more rectangular cross-sectional shape and an extended lateral taper with a completely straight lateral edge. It has been suggested that the success of the original polished, flat-back Charnley femoral component was also in part of its acting as a taper-slip stem. .,3 $^{2,3}$

The original Exeter stem implanted between 1970 and 1976 was a collarless, polished, double-tapered stem and medium-term results have been excellent with good survival ${ }^{4,5}$ and preservation of the cement mantle, the cementbone interface, and minimal osteolysis. ${ }^{4,6-9}$ The importance of the polished surface became apparent when the rougher matt surface was introduced on the Exeter stem in 1976, which performed substantially worse. . $^{8,10}$

The purpose of this study was to present the minimum ten-year clinical and radiological follow-up results of the collarless polished tapered stem when used for primary total hip replacement (THR). 


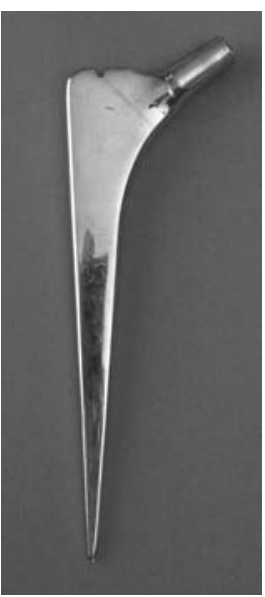

Fig. 1a

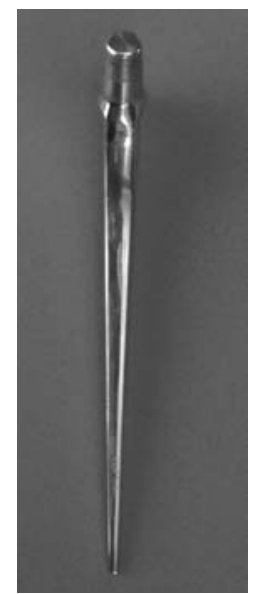

Fig. 1b
Photographs showing the cementless polished tapered stem. The broad proximal cross-section provides rotational stability. The double taper evenly loads the cement mantle and the progressive distally diminishing cross-section minimises the stress riser at the tip of the stem.

\section{Patients and Methods}

Between November 1992 and November 1995, 191 consecutive THRs were performed in 175 patients using cemented, stainless steel collarless polished tapered femoral stems. During the period of follow-up, 63 patients $(36 \%$, 68 hips), died, which is similar to published mortality data at ten years. ${ }^{9,11-13}$ One other hip was lost as the patient required a hindquarter amputation for vascular disease. This left a study cohort of 111 patients with 122 THRs with a mean follow-up of 11.08 years (10 to 12.8 ).

The pre-operative diagnosis in the hips of the surviving patients was hypertrophic osteoarthritis (OA) in 49 of the 122 hips $(40 \%)$, atrophic OA or rheumatoid arthritis (RA) in $53(43 \%)$, developmental dysplasia of the hip (DDH) in ten $(8 \%)$, avascular necrosis (AVN) in six hips $(5 \%)$, Perthes' disease in one $(1 \%)$, Paget's disease in one $(1 \%)$ and fracture in two $(2 \%)$, comprised the remaining $9 \%$. There were 77 women and 33 men with a mean age at operation of 62.3 years ( 19 to 83 ). One of the surviving patients who had bilateral THRs was too frail to be assessed radiologically after ten years, so that radiological data were available on 110 patients (120 hips) and clinical data available on all 111 patients (122 hips).

Surgical technique. The procedures were performed by two consultants' teams at the same orthopaedic centre using the posterolateral approach to the hip in all but three cases, for which the transgluteal approach was used. The femoral canals were prepared in accordance with the manufacturer's guidelines, using rasps that allowed the accommodation of a $2 \mathrm{~mm}$ cement mantle around the stem. We did not perform a posterior repair of the capsule or divided short rotators. Contemporary cementing techniques were used in all procedures and included the use of a Hardinge cement restrictor (Howmedica Ltd, London, United Kingdom), pressurised lavage, retrograde introduction of cement with a cement gun and a proximal femoral cement pressuriser. Patients younger than 65 years of age received uncemented Harris-Galante I acetabular components (Zimmer Ltd, Swindon, United Kingdom). Patients older than 65 received cemented flanged acetabular components (Charnley Elite; DePuy Ltd, Leeds, United Kingdom), or a Zimmer flanged acetabular component (Zimmer Ltd). In all THRs, $28 \mathrm{~mm}$ femoral heads were used except when the size of the acetabulum was less than $50 \mathrm{~mm}$, when a $22 \mathrm{~mm}$ head was implanted. Palacos R cement with gentamicin (KirbyWarrick Ltd, Suffolk, United Kingdom) was used in all procedures. All patients received a spinal anaesthetic unless it was medically contraindicated, and in addition, a light general anaesthetic with a laryngeal mask and spontaneous respiration was given to most patients. Systolic blood pressure was generally maintained at approximately $100 \mathrm{mmHg}$.

Clinical assessment. Clinical outcome was assessed using the Harris Hip score (HHS). ${ }^{14}$ Radiological outcome was determined from anteroposterior (AP) radiographs of the pelvis and lateral views of the affected hips. Radiographs were taken immediately post-operatively and at three months. Subsequent radiological follow-up was variable, but all surviving patients had a radiograph taken at their last follow-up after a minimum of ten years. Radiological assessments were performed by two authors (BJB and PJY) and reviewed by the senior author (GCB).

Radiological assessment. We used well-recognised assessment techniques to standardise the radiological and clinical evaluation to allow easier comparison with other prostheses, as recommended by Johnston et al. ${ }^{15}$

The quality of the cement mantle was evaluated on the AP, and lateral radiographs using the system described by Barrack et $\mathrm{al}^{15,16}$ for each of the Gruen zones ${ }^{17}$ and as extended by Johnston et al. ${ }^{15}$ Minimum cement-mantle thicknesses were measured in all 14 zones of the stem (Fig. 2) and three zones around the acetabular component. ${ }^{18}$

Alignment and subsidence of the prostheses were measured directly from calibrated films. The radiological landmarks used for measuring subsidence were the greater trochanter, the proximolateral cement mantle and the shoulder of the prosthesis, as described by the Exeter group. ${ }^{4}$ Our validation of this measurement technique for this stem, using digitised computer-assisted methods and confirmed using two assessors (PJY, and another who was not an author) repeating the measurements, indicates an accuracy $\pm 0.3 \mathrm{~mm}$. Radiolucent lines $>1 \mathrm{~mm}$ wide and $>5 \mathrm{~mm}$ long at the stem-cement and the cement-bone interface in the early post-operative and ten-year post-operative radiographs were identified in the 14 femoral zones of interest. 


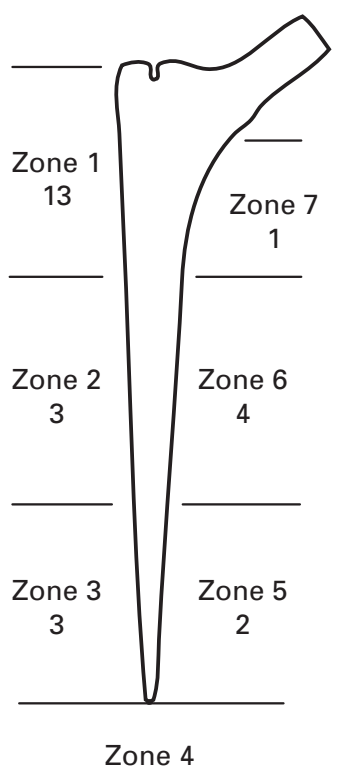

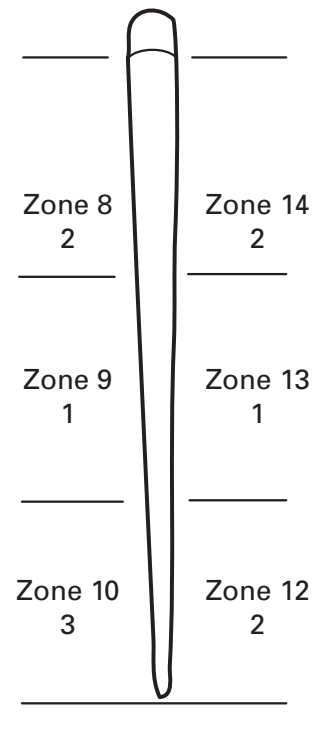

Zone 11
Fig. 2

Drawing showing an analysis of the cement mantle defects by Gruen zone. ${ }^{17}$

Osteolysis was defined as a new cystic lesion with endosteal scalloping and/or migration, which had not been recorded on the post-operative radiograph. ${ }^{19}$

Proximal/medial bone resorption was defined using the criteria described by Engh et $\mathrm{al}^{20}$ (Table I), and ectopic ossification was defined using the criteria described by Brooker et al. ${ }^{21}$

Canal filling was measured at the mid-point of the lesser trochanter and divided into the three categories of metal implant, total cement and total cancellous bone.

Acetabular wear was measured by the technique described by Latimer and Lachiewicz. ${ }^{22}$ Kaplan-Meier survival curves with $95 \%$ confidence intervals (CI) were constructed for the stem, with endpoints of revision for osteolysis or aseptic loosening, and for revision surgery for any cause, as described by Dobbs. ${ }^{23}$

A subsidence curve was derived as a line of best fit from the scattergraph of subsidence measurements.

Statistical methods. Statistical significance was assumed if $\mathrm{p}<0.05$.

\section{Results}

The fate of all stems was known, with none having been revised for aseptic loosening or osteolysis. Of the hips in patients who had died during the study period, none was revised or assessed as failing at last follow-up.

Clinical results. The mean pre-operative HHS was 39 (20 to 61 ), and the mean post-operative score was 86 (47 to 100). Excellent scores according to the HHS ${ }^{14}$ were reported in $40 \%$ of patients (48), good in 35\% (42), fair in
Table I. Proximal stress shielding by Engh grade 20

\begin{tabular}{ll}
\hline Engh grade & Number of hips (\%) \\
\hline 0 & $15(13)$ \\
1 & $62(53)$ \\
2 & $31(27)$ \\
3 & $8(7)$ \\
4 & $0(0)$ \\
\hline
\end{tabular}

$17 \%(20)$, and poor in $8 \%(10)$. There did not appear to be any relationship between the HHS and the radiological appearance, the age of the patient, the pre-operative diagnosis or the magnitude of subsidence.

Radiological results. In 91 of the 120 hips (76\%) there was complete cement filling of the medullary cavity (Barrack grade A). There were no hips with localised radiolucent lines (grade B) although some of the hips with cement mantle defects (grade C) had isolated radiolucent lines. In 24 hips $(20 \%)$ there was a full-thickness defect in the cement mantle (Barrack grade C), ${ }^{16}$ although all of these defects were less than $3 \mathrm{~mm}$ long and were most common in Gruen zone 1 . In four hips $(3.3 \%)$ the cement mantle was a Barrack grade D, with no cement covering the distal stem and centraliser (Fig. 2).

Alignment and subsidence. All stems were inserted within $5^{\circ}$ of neutral alignment in the AP plane. One stem was in more than $3^{\circ}$ varus, and six were in $3^{\circ}$ to $5^{\circ}$ of valgus. Only one stem underwent a change of alignment over ten years. This occurred in a patient with active Paget's disease, where the femur continued to remodel around the cement mantle. This was classified as a radiological failure, although the patient has not been revised because of her poor general health.

Only two hips had measurable migration of the stemcement construct at the cement-bone interface: one in the patient with Paget's disease, where $1 \mathrm{~mm}$ of migration was found at 12 years, and one in a patient with primary osteonecrosis of the femoral head, where $0.5 \mathrm{~mm}$ migration was observed at 12.5 years. Additionally, these two hips were the only ones to subside more than $5 \mathrm{~mm}$ at the stem-cement interface over the study period, despite both patients' cement mantles initially being complete (Barrack grade A). The cement mantle of the hip with osteonecrosis of the femoral head appeared to remain intact despite the subsidence, except for a distal mantle fracture at the tip of the stem. Interestingly, although we would classify this as a radiological failure, the patient retains a high level of function, is pain free, and has a HHS of 100 points.

One additional hip had a cement-mantle fracture in a male patient who weighed $102 \mathrm{~kg}$, where the initial cement mantle was poor with a defect in Gruen zone 6 . The stem subsided $2.5 \mathrm{~mm}$ at the stem-cement interface over ten years, with lucent lines in zones $1,2,6$, 7, 8, 9 and 14 and was considered probably radiologically loose. 


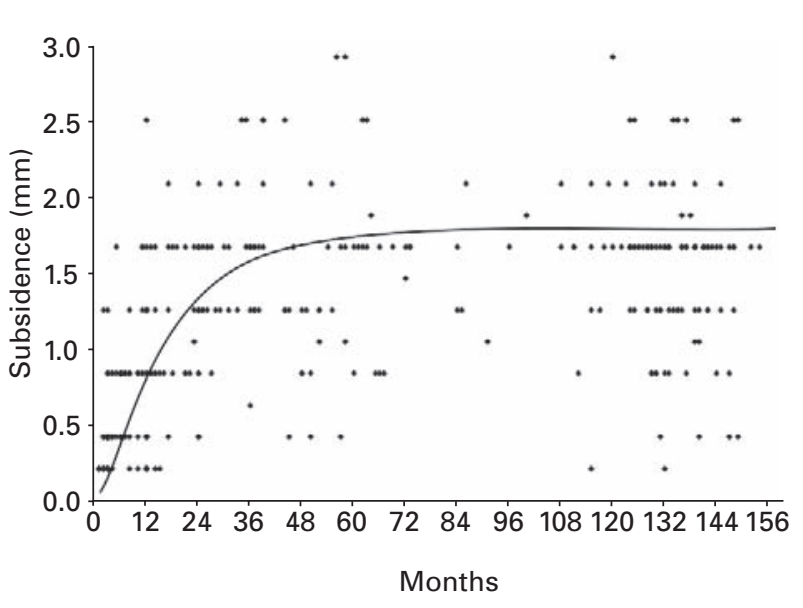

Fig. 3

Graph showing subsidence ( $\mathrm{mm}$ ) of 120 cementless polished tapered stems in 110 patients over ten years. Curve derived from line of best fit.

The mean vertical subsidence of the femoral stems at the stem-cement interface was $1.95 \mathrm{~mm}(0.21$ to 24$)$. The mean rate of subsidence was $0.18 \mathrm{~mm}$ per year (0.02 to 2.16), with a mean rate of $0.80 \mathrm{~mm}(0.02$ to 2.5$)$ in the first year, slowing to a mean of $0.12 \mathrm{~mm}$ per year $(0.02$ to 2.16$)$ after two years (Fig. 3). Subsidence was weakly associated with cement-mantle defects, especially at the tip of the stem (Barrack grade D). In hips with grade A cementing technique, the median subsidence rate was $1.67 \mathrm{~mm}$ over ten years (interquartile range (IQR), 1.25 to 1.67), whereas hips with mantle defects at the tip (Barrack grade D) had a median subsidence rate of $2.5 \mathrm{~mm}$ over ten years (IQR, 1.67 to 4.58 ). However, these differences did not achieve statistical significance (Kruskal-Wallis test, $\mathrm{p}=0.15$ ). Subsidence was significantly related to the thickness of the cement: there was less subsidence with greater cement thickness (KruskalWallis test, $\mathrm{p}=0.004$ ) (Fig. 4). There was no relationship between subsidence and the age of the patient, weight, gender, calcar cement thickness or stem alignment (all KruskalWallis test, $\mathrm{p}>0.59$ ).

Radiolucent lines and osteolysis. Of the 120 hips followed radiologically for a minimum of ten years, there were four $(3 \%)$ in which radiolucent lines were present at the cementbone interface in one or more zones. Three of these were progressive, and in one hip they involved $50 \%$ or more of the cement-bone interface and this hip was considered probably loose. Osteolysis was apparent in only seven patients $(5.8 \%)$, with the majority of affected zones (16 of 28 ) in the proximal Gruen zones (1, 7, 8 and 14). Osteolysis was strongly associated with acetabular component wear ( $t$-test, $\mathrm{p}=0.004)$. Femoral osteolysis was more likely with thinner cement mantles at the calcar ( $t$-test, $\mathrm{p}=0.04)$, but not related to thinner mantles at the greater trochanter ( $t$-test, $\mathrm{p}=0.89)$.

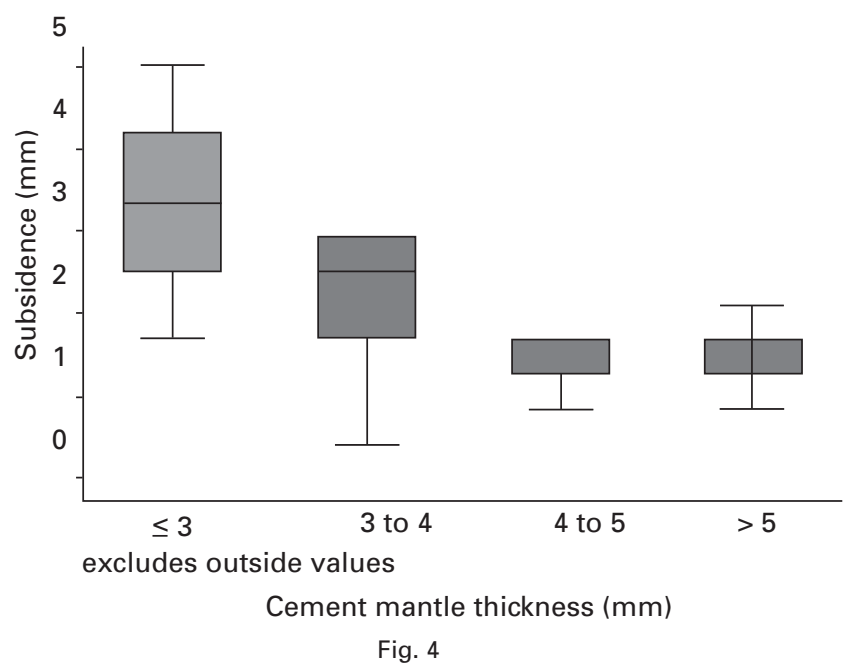

Box plot showing median (range) subsidence $(\mathrm{mm}$ ) of the stem at the stem-cement interface and its relationship to the mean thickness of the cement mantle.

Two patients (other than the patient with Paget's disease) have been classified as radiological failures at their ten-year follow-up and await revision (Table II). Both were active at the time of implantation, one was aged 47 years and the other was a working farmer. Both had high total polyethylene wear rates of $4 \mathrm{~mm}$ and $7 \mathrm{~mm}$ (the mean wear rate for the whole cohort was $2.01 \mathrm{~mm}(0$ to 7$)$ ) and both have substantial periarticular osteolysis. The younger patient had undergone a childhood femoral osteotomy for dysplasia. This patient had a very narrow canal ${ }^{24}$ and required intramedullary reaming to allow introduction of the stem. Proximal bone preservation. In 77 of the hips (64\%) no or first-degree resorption ${ }^{20}$ was found in the region of the proximal/medial cortex, in 31 second-degree resorption $(26 \%)$, in eight third-degree resorption $(7 \%)$, and none had fourth-degree resorption. Resorption was not related to calcar cement thickness ( $t$-test, $\mathrm{p}=0.64$ ), but was related to the proportion of the femur occupied by the stem $(t$-test, $\mathrm{p}=0.02$ ) (Table I).

Cortical hypertrophy. Only one hip had definite cortical hypertrophy at ten years. This was present in Gruen zones 3 and 5 . This male patient weighed $64 \mathrm{~kg}$ and subsidence of the stem was $2.5 \mathrm{~mm}$, only slightly above the mean.

Ectopic ossification. In 67 of the patients $(58 \%)$ there was no ectopic ossification, $12(10 \%)$ showed Brooker grade I, $12(10 \%)$ grade II, $18(16 \%)$ grade III and seven $(6 \%)$ had grade IV. The range of movement was frequently restricted in the patients with grades III and IV. These higher grades were associated with hypertrophic OA, male gender, and a restriction in all movements (all Fisher's exact test, $\mathrm{p}<0.001)$. High grades were not significantly associated with pain (Fisher's exact test, $\mathrm{p}=0.26$ ).

Complications. A total of nine hips in nine patients $(8 \%)$ required re-operation: one for late metastatic infection, one 
Table II. Details of the revisions and radiological failures

\begin{tabular}{|c|c|c|c|c|c|}
\hline & Gender & Age (yrs) & Original diagnosis* & $\begin{array}{l}\text { Time to } \\
\text { revision (yrs) }\end{array}$ & Comments \\
\hline $\begin{array}{l}\text { Femoral and } \\
\text { acetabular revision }\end{array}$ & $\mathrm{F}$ & 21 & $\mathrm{DDH}$ & 7 & Metastatic infection \\
\hline Femoral revision & $\mathrm{F}$ & 68 & $\mathrm{DDH}$ & 5 & Peri-prosthetic fracture \\
\hline \multirow[t]{7}{*}{ Acetabular revisions } & M & 47 & Acetabular fracture & 0.8 & $\mathrm{HG}^{\ddagger}$ aseptic loosening, trochanteric nonunion \\
\hline & $\mathrm{M}$ & 54 & $\mathrm{DDH}$ & 5 & HG dislocation, liner exchange \\
\hline & $\mathrm{F}$ & 56 & Atrophic OA & 8 & HG dislocation, revised to captive component \\
\hline & $\mathrm{M}$ & 67 & Hypertrophic OA & 2 & HG dislocation, revised to captive component \\
\hline & $\mathrm{F}$ & 25 & Ank spond & 8 & HG liner exchange for high wear \\
\hline & $\mathrm{M}$ & 69 & Hypertrophic OA & 7 & Acetabular aseptic loosening (Zimmer cemented to HG) \\
\hline & $\mathrm{F}$ & 59 & Atrophic OA & 1 & HG dislocation, liner exchange HG \\
\hline Other losses & M & 42 & AVN & 8 & Vascular disease, hindquarter amputation \\
\hline \multirow{3}{*}{$\begin{array}{l}\text { Radiological stem } \\
\text { failure }\end{array}$} & $\mathrm{F}$ & 74 & Paget's disease & $\mathrm{N} / \mathrm{A}^{\dagger}$ & Femur remodelled \\
\hline & M & 73 & Atrophic OA & $\mathrm{N} / \mathrm{A}$ & Zimmer cemented, high wear, osteolysis \\
\hline & $\mathrm{F}$ & 47 & DDH/osteotomy & $\mathrm{N} / \mathrm{A}$ & HG canal reamed, high wear, osteolysis \\
\hline
\end{tabular}

* DDH, developmental dysplasia of the hip; OA, osteoarthritis; Ank spond, ankylosing spondylitis; AVN, avascular necrosis

$\dagger \mathrm{N} / \mathrm{A}$, not applicable

$\ddagger$ HG, Harris-Galante

for traumatic peri-prosthetic fracture (not associated with loosening or osteolysis), one for liner wear, two for acetabular component loosening, and four for dislocation (Table II). Two of the acetabular revisions were complicated by deep infection requiring two-stage revision.

Overall, 13 hips $(11 \%)$ had a dislocation which was significantly related to the use of $22 \mathrm{~mm}$ femoral heads (Fisher's exact test, $\mathrm{p}=0.05$ ) (4 of $1322 \mathrm{~mm} v s 9$ of $10428 \mathrm{~mm}$ ), but not related to gender, age, type of acetabular component, acetabular wear, the use of collared heads, or inadequate restoration of femoral offset (all Fisher's exact test and $t$-test, $\mathrm{p}>0.30)$. Only one patient in the series had a positive Trendelenburg sign, and this patient had a posterior approach.

Survival. Survival for the stems with an endpoint of revision for aseptic loosening or osteolysis at ten years was 100\%. Survival for the stems with an endpoint of revision for any cause at ten years was $95.9 \%$ (95\% CI 87.8 to 96.8 ).

\section{Discussion}

In the last ten years, the use of collarless, double-tapered, polished stems designed to subside within the cement mantle has become popular in parts of Europe and Australia. Currently, in the United Kingdom, over $70 \%$ of cemented THRs are of this type. ${ }^{25}$ The clinical and radiological success of this type of stem has been reported in several series ${ }^{4,5,9,26-28}$ and in the Scandinavian joint registries. $^{29,30}$ Our final HHS are comparable to those of other series of cemented stems to report the HHS at ten years, including other cemented tapered stems. , $^{9,12,16,31-35}$

A clear distinction must be made between subsidence of polished tapered stems within the cement mantle, which is considered benign, ${ }^{36}$ and subsidence at the cement-bone interface, which is always associated with failure, when above a certain threshold. ${ }^{37,38}$ We believe that an excessive rate of subsidence of this type of stem at the stem-cement interface is an important indicator of the quality of the stem-cement bone-construct. In this study, subsidence was greater in those stems with poorer Barrack cement grades, although this did not reach statistical significance $(\mathrm{p}=0.15)$, and was significantly less with thicker cement mantles $(p=0.004)$. The association of stem-cement subsidence with the quality of cement mantles is in agreement with the findings of the Exeter group, although the subsidence in their report was more strongly related to cementing grade $(\mathrm{p}=0.03) .{ }^{9}$ We have also previously reported a direct relationship between subsidence and defects in the cement mantle ( $\mathrm{p}=0.001)$ using the Exeter universal stem. ${ }^{28}$

Much debate still surrounds what constitutes an optimal cement mantle thickness, ${ }^{37,39}$ and whether defects in the mantle are detrimental. ${ }^{40-44}$ Thinner cement mantles are associated with mantle defects, an increased risk of mantle fracture, and increased subsidence of the stem within the mantle. ${ }^{31,39}$ We recommend a minimum mantle thickness of $2 \mathrm{~mm}$, but it is unclear what the upper limit of the thickness should be. Furthermore, we believe that completeness of the cement mantle is far more important than its absolute thickness. Careful preparation of the femoral canal, and possibly selecting a stem smaller than the last broach, is likely to reduce the incidence of defects and may reduce subsidence.

The cement mantles in the present series were extremely good. Using the most critical analytical method in all 14 Gruen zones, ${ }^{16} 76 \%$ of the mantles were complete (Barrack grade A) and $20 \%$ had a defect. All cement mantle defects were less than $3 \mathrm{~mm}$ in length and were usually in zones 1 
or 14 , where bone was not adequately removed from the greater trochanter, or where the prosthesis touched the remnants of the trochanteric fossa during implantation. Barrack $\mathrm{C}$ and $\mathrm{D}$ cement grades were not associated with failure, unlike with other types of stem, ${ }^{6,16}$ but osteolysis was significantly associated with thinner cement at the calcar (Gruen zone 7) ( $\mathrm{p}=0.04)$ but not in Gruen zone 1, and strongly associated with polyethylene wear. On the basis of these findings, we suggest that in the presence of wear particles, the collarless polished tapered stem reduces the likelihood of osteolysis by minimising access to the cementbone interface because of the stem's straight lateral edge and its purely vertical subsidence pattern. When there is inadequate cement at the calcar, osteolysis is more likely to occur, perhaps because of microfracture and associated calcar bone loss through stress shielding.

Varus malposition of the stem has been associated with failure in several studies relating to the associated deficient mantles in Gruen zone $7 .{ }^{45}$ In this series, five stems were in mild varus $\left(3^{\circ}\right.$ to $\left.5^{\circ}\right)$, but none was in more than $5^{\circ}$ varus. These stems were not associated with radiological loosening, excessive subsidence or osteolysis. Valgus positioning was also not a problem.

We do not recommend reaming the femoral canal when using this type of stem. In a series of Exeter stems implanted in small femurs in Hong Kong, ${ }^{32}$ all four of the stems that had been implanted in reamed femurs were revised before nine years. In our series, the only collarless polished tapered stem that was implanted in a reamed canal is awaiting revision. We believe that reaming causes incomplete cement mantles as a result of over-sizing of the stems and the loss of the supporting cancellous bone, with a resulting failure of an adequate cement-bone interface.

All conventional THRs alter the loading of the proximal femur and lead to varying amounts of bone loss and redistribution, especially around the calcar. The collarless polished tapered stem appears to preserve proximal bone relatively well, suggesting good proximal loading. Severe and moderate resorption occurred almost twice as frequently in Engh's ${ }^{20}$ series of cementless stems compared to ours $(7 \%$ vs $12 \%)$. The use of larger, stiffer collared polished tapered stems was negatively associated with proximal bone preservation, with a significant association with higher Engh resorption grades $(\mathrm{p}=0.02)$. The virtual absence of distal cortical hypertrophy further suggests that load transfer from the stem to the bone is nearly physiological. ${ }^{46}$ This is achieved through the double-taper design, which increases the flexibility of the stem as it narrows distally. ${ }^{7}$

Our rate of dislocation was high at $11 \%$ in the hips surviving more than ten years. This may have been related to the limited range of offsets for the collared polished tapered stem initially available, and/or our failure to repair the posterior capsule and short rotators throughout the study.

High-grade ectopic ossification was a frequent finding and was significantly related to a restriction in movement, but not to pain or HHS. To the best of our knowledge, this is the first series in which the grade of ectopic ossification has had such a significant correlation with the range of movement. This may be because of the large proportion of hips with hypertrophic OA $(40 \%)$, or to our method of preparing the femoral canal.

Summary. This study confirms the effectiveness of the collarless, polished, tapered stem principle using contemporary cementing techniques.

The taper-slip mechanism of fixation of the polished collared polished tapered and Exeter stems is different from that of prostheses designed to be perfectly stable after implantation (composite beam). Subsidence of the polished, collarless, tapered stem at the stem-cement interface is self-limiting and not associated with aseptic loosening or endosteal bone lysis. It is beneficial for polished tapered stems to subside, as this enhances stability, load distribution, sealing the access to the proximal metaphysis to articular debris, and protects the cement mantle. Previously published conclusions ${ }^{37,38}$ predicting failure of the femoral stem on the basis of the subsidence patterns of other stem designs cannot be used to predict failure in tapered designs such as the collared polished tapered.

No benefits in any form have been received or will be received from a commercial party related directly or indirectly to the subject of this article.

\section{References}

1. Shen G. Femoral stem fixation: an engineering interpretation of the long-term outcome of Charnley and Exeter stems. J Bone Joint Surg [Br] 1998;80-B:754-6.

2. Charnley J. A biomechanical analysis of the use of cement to anchor the femoral head prosthesis. J Bone Joint Surg [Br] 1965;47-B:354-63.

3. Loudon JR, Charnley J. Subsidence of the femoral prosthesis in total hip replacement in relation to the design of the stem. J Bone Joint Surg [Br] 1980;62-B:450-3.

4. Fowler JL, Gie GA, Lee AJ, Ling RS. Experience with the Exeter total hip replacement since 1970. Orthop Clin North Am 1988;19:477-89.

5. Franklin J, Robertsson 0, Gestsson J, Lohmander L, Ingvarsson T. Revision and complication rates in 654 Exeter total hip replacements, with a maximum follow-up of 20 years. BMC Musculoskeletal Disord 2003;4:1-5.

6. Bannister G. Mechanical failure in the femoral component in total hip replacement. Orthop Clin North Am 1988;19:567-73.

7. Huiskes R, Verdonschot N, Nivbrant B. Migration, stem shape, and surface finish in cemented total hip arthroplasty. Clin Orthop 1998;355:103-12.

8. Middleton RG, Howie DW, Costi K, Sharpe P. Effects of design changes on cemented tapered femoral stem fixation. Clin Orthop 1998;355:47-56.

9. Williams HD, Browne G, Gie G, et al. The Exeter universal cemented femoral component at 8 to 12 years: a study of the first 325 hips. J Bone Joint Surg [Br] 2002;84B:324-34.

10. Rockborn P, Olsson SS. Loosening and bone resorption in Exeter hip arthroplasties: review at a minimum of five years. J Bone Joint Surg [Br] 1993;75-B:865-8.

11. Iwase T, Wingstrand I, Persson BM, et al. The scan hip total hip arthroplasty: radiographic assessment of 72 hips after 10 years. Acta Orthop Scand 2002;73:54-9.

12. Issack P, Botero $\mathbf{H}$, Hiebert $\mathbf{R}$, et al. Sixteen-year follow-up of the cemented spectron femoral stem for hip arthroplasty. J Arthroplasty 2003;18:925-30.

13. Ramiah RD, Ashmore AM, Whitley E, Bannister GC. Ten-year life expectancy after primary total hip replacement. J Bone Joint Surg [Br] 2007;89-B:1299-302.

14. Harris WH. Traumatic arthritis of the hip after dislocation and acetabular fractures: treatment by mold arthroplasty: an end result study using a new method of evaluation. J Bone Joint Surg [Am] 1969;51-A:737-55.

15. Johnston RC, Fitzgerald RH, Harris WH, et al. Clinical and radiological evaluation of total hip replacement. J Bone Joint Surg [Am] 1990;72-A:161-8. 
16. Barrack R, Mulroy RD, Harris WH. Improved cementing techniques and femoral component loosening in young patients with hip arthroplasty: a 12-year radiographic review. J Bone Joint Surg [Br] 1992;74-B:385-9.

17. Gruen TA, McNeice GM, Amstutz HC. "Modes of failure" of cemented stem-type femoral components: a radiographic analysis of loosening. Clin Orthop 1979;141:17 27.

18. DeLee J, Charnley J. Radiological demarkation of cemented sockets in total hip replacement. Clin Orthop 1976;121:20-32.

19. Joshi RP, Eftekhar NS, McMahon DJ, Nercessian OA. Osteolysis after Charnley primary low-friction arthroplasty: a comparison of two matched paired groups. J Bone Joint Surg [Br] 1998;80-B:585-90.

20. Engh CA, Bobyn JD, Glassman AH. Porous-coated hip replacement: the factors governing bone ingrowth, stress shielding and clinical results. J Bone Joint Surg $[\mathrm{Br}]$ 1987;69-B:45-55.

21. Brooker AF, Bowerman JW, Robinson RA, Riley LH Jr. Ectopic ossification following total hip replacement: incidence and a method of classification. J Bone Joint Surg [Am] 1973;55-A:1629-32.

22. Latimer HA, Lachiewicz PF. Porous-coated acetabular components with screw fixation: five to ten-year results. J Bone Joint Surg [Am] 1996;78-A:975-81.

23. Dobbs HS. Survivorship of total hip replacements. J Bone Joint Surg [Br] 1980;62B:168-73

24. Dorr L, Faugere MC, Mackel AM, et al. Structural and cellular assessment of bone quality of proximal femur. Bone 1993;3:231-42.

25. No authors listed. NJR: National Joint Registry for England and Wales 2nd annual report. www.njrcentre.org.uk (date last accessed 5 December 2007).

26. Wroblewski BM, Siney PD, Fleming PA. Triple taper polished cemented stem in total hip arthroplasty: rationale for the design, surgical technique, and 7 years of clinical experience. J Arthroplasty 2001;16(Suppl 1):37-41.

27. Glyn-Jones S, Gill HS, Beard DJ, McLardy-Smith P, Murray DW. Infleunce of stem geometry on the stability of polished tapered cemented femoral stems. J Bone Joint Surg [Br] 2005;87-B:921-7.

28. Hooks, Moulder E, Yates PJ, et al. The Exeter universal stem: a minimum ten-year review from an independent centre. J Bone Joint Surg [Br] 2006;88-B:1584-90.

29. Malchau H, Herberts P, Garelick G, Soderman P, Eisler T. Prognois of total hip replacements. Procs 69th American Academy of Orthopaedic Surgeons annual meeting, 2002.

30. Lucht U. The Danish Hip Arthroplasty Register. Acta Orthop Scand 2000;71:433-9.

31. Mulroy RD, Harris WH. The effect of improved cementing techniques on component loosening in total hip replacement: an 11 year radiographic review. J Bone Joint Surg $[B r] 1990 ; 72-B: 757-60$
32. Chiu KH, Shen WY, Cheung KW, Tsui HF. Primary Exeter total hip arthroplasty in patients with small femurs: a minimal of 10 years follow-up. J Arthroplasty 2005;20:275-81

33. Berli BJ, Schäfer D, Morscher EW. Ten-year survival of the MS-30 matt-surfaced cemented stem. J Bone Joint Surg [Br] 2005;87-B:928-33.

34. Clohisy JC, Harris WH. Primary hybrid total hip replacement, performed with insertion of the acetabular component without cement and a precoat femoral component with cement: an average ten-year follow-up study. J Bone Joint Surg [Am] 1999;81A:247-55.

35. Lachiewicz PF, Messick P. Precoating femoral component in primary hybrid total hip arthroplasty: results at a mean 10-year follow-up. J Arthroplasty 2003;18:1-5.

36. Stefánsdóttir A, Franzén H, Johnsson R, Ornstein E, Sundberg M. Movement pattern of the Exeter femoral stem: a radiostereometric analysis of 22 primary hip arthroplasties followed for 5 years. Acta Orthop Scand 2004;75:408-14.

37. Walker PS, Mai SF, Cobb AG, Bentley G, Hua J. Prediction of clinical outcome of THR from migration measurements on standard radiographs: a study of cemented Charnley and Stanmore femoral stems. J Bone Joint Surg [Br] 1995;77-B:705-14.

38. Freeman MA, Plante-Bordeneuve P. Early migration and late aseptic failure of proximal femoral prosthesis. J Bone Joint Surg [Br] 1994;76-B:432-8.

39. Goldberg BA, Al-Habbal G, Noble PC, et al. Proximal and distal centralizers in modern cemented hip arthroplasty. Clin Orthop 1998;349:163-73.

40. Jasty M, Maloney WJ, Bragdon CR, et al. The initiation of failure in cemented femoral components of hip arthroplasties. J Bone Joint Surg [Br] 1991;73-B:551-8.

41. Kawate K, Maloney WJ, Bragdon CR, et al. Importance of a thin cement mantle: autopsy studies of eight hips. Clin Orthop 1998;355:70-6

42. Powers CM, Lee IY, Skinner HB, Keyak JH. Effects of distal cement voids on cement stress in total hip arthroplasty. J Arthroplasty 1998;13:793-8.

43. Harrigan TP, Kareh JA, O'Connor DO, Burke DW, Harris WH. A finite element study of the initiation of failure of fixation in cemented femoral total hip components. J Orthop Res 1992;10:134-44.

44. Breusch SJ, Lukoschek, Kruetzer J, Brocai D, Gruen TA. Dependency of cemen mantle thickness on femoral stem design and centralizer. J Arthroplasty 2001;16:64857

45. Ebramzadeh E, Sarmiento A, McKellop HA, Llinas A, Grogan W. The cement mantle in total hip arthroplasty: analysis of long-term radiographic results. J Bone Joint Surg [Am] 1994;76-A:77-87.

46. Gibbons CE, Davis AJ, Amis AA, et al. Periprosthetic bone mineral density changes with femoral components of differing design philosophy. Int Orthop 2001;25:89-92. 